\title{
LOS SABERES DEL EDUCADOR EN EL DISCURSO PEDAGÓGICO DE JIDDU KRISHNAMURTI
}

\author{
Margarita Armenta Beltrán* \\ Universidad Autónoma de Sinaloa \\ Universidad Pedagógica del Estado de Sinaloa
}

\section{RESUMEN}

En el marco del Seminario sobre Teorías implícitas y conocimiento práctico profesional docente, se presentó este trabajo, cuyo propósito fue evidenciar los saberes del educador implícitos en el discurso pedagógico de Jiddu Krisnhnamurti, como un ejemplar de la pedagogía oriental; en primer lugar, se presentan las principales ideas que les subyacen a los saberes que, de acuerdo con Krishnamurti, todo educador debe conocer. Una vez hecho esto, se contrastan dichas ideas con el PPI (perfil, parámetros e indicadores) del Servicio Profesional Docente Mexicano para visibilizar su presencia en el pensamiento de los profesores mexicanos; efectivamente, los hallazgos indican que se pueden percibir de manera difusa tales ideas en el pensamiento reflejado en el mencionado PPI.

Palabras Clave: pedagogía oriental, teoría educativa, educación en Krishnamurti, teoría de la profesión docente, conocimiento profesional.

\section{THE EDUCATOR'S KNOWLEDGE IN JIDDU KRISHNAMURTI'S PEDAGOGICAL DISCOURSE}

\section{Abstract}

In the framework of the Seminar on Implicit Theories and Teacher's Practical Professional Knowledge, this work was presented whose purpose was to make evident the educator's knowledge implicit in the pedagogical discourse of Jiddu Krisnhnamurti, as an example of oriental pedagogy; the main ideas that underlie knowledge according to Krishnamurti, that every educator should know, are described. Once this is done, these ideas are contrasted with the PPI (Profile, Parameters and Indicators) of the Mexican Teaching Professional Service to make visible its presence in the thinking of Mexican professors; indeed, the findings indicate that such ideas can be diffused in the thinking reflected in the aforementioned PPI. KEYwORDS: oriental pedagogy, educational theory, education in Krishnamurti, theory of the teaching profession, professional knowledge. 


\section{INTRODUCCIÓN}

Dado que los estudios sobre las ideas pedagógicas de Krishnamurti son escasos o inexistentes, nos ha parecido necesario y oportuno presentar algunas notas biográficas y los pensamientos más destacados en los que insiste de manera recurrente en sus charlas, en la idea de contextualizar los saberes que el educador debe internalizar para ser un docente de los centros escolares Krishnamurti. Clarificando lo anterior, estaremos en condiciones de contrastar con el PPI (perfil, parámetros e indicadores) del Servicio Profesional Docente de los profesores mexicanos.

\section{JIDDU KRISHNAMURTI. ALGUNAS NOTAS BIOGRÁFICAS}

El pensamiento de Krishnamurti es sutil y complejo; se dice esto porque se entretejen en la expresión de sus ideas formas intelectuales no convencionales con las que creó un puente entre lo secular y lo sagrado, como una consciencia que ve las cosas como son, libres de las distorsiones del condicionamiento y las limitaciones del pensamiento, que trasciende los imperativos del «yo» a favor de la compasión, el amor desinteresado, el silencio, la belleza y la alegría.

Aunque era enemigo de las etiquetas, fue considerado un filósofo, un psicólogo, un sociólogo no convencional, un investigador de la conciencia humana en íntima relación con lo social. Se caracterizó por no ser un erudito, ni acumulador de conocimientos, ni recolector de citas, ni constructor de sistemas o estructuras conceptuales. En cambio, se dice de él que fue un pensador atípico (Alarcón, 2007), un descifrador de los mecanismos de la mente tanto conscientes como inconscientes, un "sintetista» ${ }^{1}$ frente a toda tradición analítica, un examinador de la compleja estructura de lo real universal, un investigador puro de altos vuelos de un bucle que pasa del individuo a la sociedad y de la sociedad al individuo, y que configura lo real como un proceso dinámico entre el pensador y el pensamiento.

*E-mail: maggy@uas.edu.mx. Es maestra en Educación en el campo de la formación docente por la Escuela Normal de Sinaloa y doctora en Educación por la Universidad Autónoma de Sinaloa. Forma parte del Sistema Nacional de Investigadores Nivel Candidata/CONACyT, México. Es integrante de la Red Temática CONACyT de Investigación de Educación Rural. Sus intereses de investigación se enfocan en el pensamiento y conocimiento profesional, así como en las estrategias de afrontamiento que utilizan los profesores que trabajan en contextos adversos, tales como educadores de niños y niñas migrantes y de escuelas rurales.

${ }^{1}$ Un sintetista es un pensador creativo que percibe el mundo en términos opuestos; tiende a poner en duda todo y a ser escéptico, puede crear nuevas ideas a partir del conflicto mediante la confrontación y la discusión abierta. Mediante la síntesis se procede con un pensamiento ordenado hacia la reunión de todas las partes, estableciendo un nuevo sentido y una lógica de interrelaciones entre las unidades de conocimiento desde los más simples hasta los más complejos: «Síntesis refiera a unión, composición, sea de las partes para construir el todo, del concepto y la realidad, o de la afirmación y la negación para alcanzar un nivel superior de conocimiento» (Rueda, 2007). 
En síntesis, su pensamiento está dirigido a profundizar y penetrar en la naturaleza real de los problemas del mundo, a hacer explícitos los procesos y motivaciones más o menos ocultos por los que pensamos, sentimos y actuamos los seres humanos, que nos conduzcan a comprender lo que realmente somos. Posicionado en la realidad del momento - una sociedad convulsionada en la que todas las ideologías y religiones han agotado sus propias pretensiones-, deseaba que el comprender el mundo fuera un descubrimiento personal de cada individuo mediante un nuevo modo de entender la vida, un nuevo humanismo y una nueva educación del saber, del ser, del hacer y del convivir.

Krishnamurti no era un educador formal; carecía de títulos que lo autorizaran a dedicarse a la educación o formar centros educativos. Sin embargo, se le ha descrito como un maestro revolucionario que trabajó incesantemente para despertar la inteligencia de la gente, su sentido de responsabilidad, una chispa de descontento; su compromiso con este despertar de la consciencia se fundaba en una fuerte pasión moral que lo impulsaba a la búsqueda de la buena sociedad, basada en los valores correctos y en las relaciones correctas, entendidos de maneras no convencionales. Tenía una gran esperanza en la educación como agente de transformación interna (psicológica) y de cambio social. En ese sentido, su interés se centró en hacer al hombre libre, en la libertad como forma de ser, sobre la base de un amor constante a la naturaleza, un compromiso firme y la responsabilidad individual en la tarea de lograr una sociedad mejor (Thapan, 2001).

Las escuelas de la FKI (Fundación Krishnamurti de la India) se encuentran en lugares de gran belleza rodeadas de naturaleza, pues, de acuerdo con Krishnamurti, el espacio físico y el aprendizaje en un entorno natural favorecen la armonía en las relaciones entre los estudiantes, los profesores y el personal de la escuela, así como el desarrollo de una mente inquieta y creativa. También intentaba que las escuelas actuaran como una unidad, aunque fueran legal y nacionalmente independientes; originar un sentimiento de que todas las escuelas estaban trabajando para el mismo fin y descubrir cómo trasmitir e interpretar todas esas ideas mediante la enseñanza de las asignaturas (1996).

La idea de fundar escuelas le surgió al conocer el modelo de la Universidad de Berkeley, California (Blau, 2007, p. 146). En Estados Unidos fundó la Oak Gorve School en Ojai, California; en Inglaterra, la Brookwwod Park School; en India: Uttarskashi Education Center en Uttar Pradesh; Rishi Valley Education Center en Chittor District, Andhra Pradesh; Rajghat Education Center Rajghat Fort en Uttar, Pradesh; The School (KFI) Damodar Gardens en Chennai; Bal Anand Mumbai (KFI) en Dongerseg; The Valley School (KFI) Bangalores Education Center en Bangalore; y Sahyadri School Administrative Officer en Rajgurunagar.

En 1978 formó un comité de publicaciones cuya responsabilidad era divulgar sus charlas. En 1969 se estableció la American Krishnamurti Foundation y en 1970 la Indian Foundation. Desde 1997, se publica la revista anual Journal of the Krishnamurti Schools, con el propósito de documentar y crear pedagogías innovadoras y críticas dentro de un proceso de transformación de la educación.

El influjo de su pensamiento se vio reflejado en la obra de David Bohm, quien lo consideraba su mentor; también en David Peat, colaborador de Bohm; y 
en la teoría de la autopoiesis de Maturana y Varela. Viajó por todo el mundo dando charlas para divulgar sus ideas. En México estuvo entre octubre y noviembre de 1935.

Krishnamurti nació el 11 de mayo de 1895 en Manandapalle, un pequeño poblado rodeado de cerros que se encuentra entre Madrás y Bangalore, India. Murió en Ojai, California, en febrero de 1986 a la edad de 91 años.

\section{LA PEDAGOGÍA DE KRISHNAMURTI: EL VIAJE SIN SENDERO}

El mundo está en crisis. Es una realidad que nos persigue desde antes y de ahora. Krishnamurti lo decía en cada una de sus conversaciones públicas, ante lo cual inquiría a su auditorio: ¿qué podemos hacer para cambiar el mundo al mismo tiempo que a nosotros mismos? Su respuesta invitaba a que cada quien hiciera el cambio sin depender de nadie, sin guía, sin maestro o sin autoridad. Sostenía la necesidad de confrontarse con uno mismo y en la relación con el otro y con el mundo, por cuenta propia $(1975$, p. 35). Para cambiar el mundo no hay camino construido, hay que irlo haciendo sobre la propia marcha.

¿Cómo podía ocurrir esto? Sugería una indagación en nuestro mundo interior para descubrir y explorar hasta la raíz por qué aceptamos las creencias y la tradición, y comprender los motivos y las causas de esa aceptación; tales creencias -religiosas, políticas y de todo tipo-, afirmaba, separan a los hombres y crean conflicto, confusión y antagonismo, generando intolerancia. Por lo que la necesidad de cambio que él percibía tenía su origen en el entorno, causante de los grandes conflictos en las interacciones de las personas en la sociedad actual.

Aunque también afirmaba que todas las personas tenemos la común capacidad de pensar. Cada uno piensa de acuerdo a su capacidad, energía y conocimientos, de acuerdo a su experiencia y condicionamiento. La conciencia, decía, es común a toda la humanidad. En todas partes el hombre sufre ansiedad, incertidumbre, desesperación, soledad, inseguridad, celos, codicia y envidia. Estas cuestiones tensan los hilos que nos atan en nuestro convivir diario (1984).

Nuestra conciencia, afirmaba,

... incluye en sus capas más profundas, nuestros miedos. El hombre ha vivido con miedo generación tras generación; ha vivido con el placer, con la envidia, con todos los tormentos de la soledad, la depresión y el desorden; ha vivido con gran dolor con lo que él llama amor y con el perpetuo miedo a la muerte. Todo esto es nuestra conciencia, que es común a toda la humanidad (Krishnamurti, 1984).

Consideraba que era difícil comprendernos de manera total, puesto que la carga del programa - genético y social heredado generación tras generación- nos ha conducido a pensar que somos individuos separados, cuando en realidad somos seres totales. Para él, era necesario descubrir lo que significa comprenderse a uno mismo y al mundo que nos rodea. Es por eso por lo que invitaba a realizar una revisión cuidadosa de lo que significan el conocimiento, el pensamiento, la imagen, la expe- 
riencia, la actividad, la acción, la creencia, la memoria y la tradición y su influjo en nuestras mentes, que, todos juntos, impiden la comprensión de uno mismo y del entorno. Para indagar e investigar sobre ello, afirmaba, se debe afrontar el mundo con una actitud de descontento; reconocer que cada uno de nosotros está condicionado psicológica, mental e intelectualmente desde las células del cerebro para vivir con especulaciones, con conceptos, con fórmulas. Se está condicionado a no ver el peligro que ello reviste (Krishnamurti, 1975), pues las imágenes, los símbolos, los conceptos, las conclusiones, los ideales no son más que la proyección del pensamiento; y para comprender su naturaleza y realización se necesita comprender todo su proceso de construcción.

Krishnamurti reflexionó profundamente sobre estas cuestiones y sus principales causas. Mencionaremos algunas de ellas en los siguientes párrafos.

Iniciaremos con el conocimiento, del cual afirmaba que su existencia en la vida cotidiana da lugar a una actividad mecánica. El conocimiento convertido en rutina mecánica limita al cerebro y lo vuelve rígido e insensible, se expresa en las teorías que construye la mente y las convierte en dogmas que impiden ver la realidad como algo complejo. El conocimiento y la rutina mecánica tienen una relación causal recíproca, pues la parte mecánica de la vida concierne a la adquisición de conocimientos, lo cual implica aceptar el patrón de valores creado por las generaciones pasadas, repitiéndose una y otra vez en el transcurso del trayecto vital; aceptar ese patrón de valores "produce un inevitable deterioro que destruye nuestras capacidades, nuestra sensibilidad, nuestra fibra moral e intelectual» (Krishnamurti, 1978).

El pensamiento, por su parte, decía, es el resultado del pasado, del ayer y de muchos muchos ayeres. Es el resultado de las relaciones condicionadas establecidas en la mente como pasado. Por lo tanto, la mente es el resultado del pasado. Es decir, el pensar es la respuesta de la memoria. La memoria es un proceso, un residuo de experiencias, sean estas inmediatas o del pasado. El contacto, la sensación, el deseo son origen y creación de la experiencia. La experiencia deja un residuo que llamamos memoria, ya sea agradable o desagradable, provechosa o no provechosa. De ese residuo surge una respuesta que hemos llamado "pensar» condicionado por diferentes residuos ambientales y así sucesivamente. Todo nuestro proceso consciente de mirar, de pensar y de sentir tiene sus cimientos en el pasado. Además, vivimos en las capas superiores de la conciencia, en la mente superficial; es ahí donde estamos activos donde se nos plantean los problemas, los innumerables conflictos y la actividad del diario vivir y con todo ello nos sentimos satisfechos. Mas lo que está en la superficie, lo que ahí se manifiesta no es, por cierto, el contenido total de la conciencia (Krishnamurti, 2003).

Pero el pensamiento también es el resultado del conocimiento y la ignorancia; tal resultado conduce a la conformidad, la imitación y el seguimiento de un patrón que a su vez moldea la mente conforme a una estructura religiosa o social que impele al control y a la obediencia con base en la recompensa y el castigo que a su vez conducen a seguir la tradición y la continuidad. La acción (Krishnamurti, 1978), en consonancia con lo anterior, es un movimiento continuo desde el pasado interrumpido ocasionalmente con una serie de nuevas conclusiones que al mismo 
tiempo se convierten en pasado, generando conocimiento condicionado y acciones mecánicas.

De igual modo, la experiencia lo que hace es fortalecer la mente condicionada de quien la experimenta perpetuando el hábito y la rutina que conducen a un modo mecánico de vivir. El hábito es una acción reiterativa del no estar atento, que coloca a la mente dentro de un surco, de un estrecho modo de vida. Caemos en el hábito porque es el modo más cómodo de vivir y cuando se observa detenidamente, se descubre que el hábito en la relación encubre cierta cualidad de indolencia, negligencia y descuido, lo que vuelve a la mente insensible conduciéndola a un proceso degenerativo que tiene por objeto alguna forma de seguridad ilusoria a la cual aferrarse.

El origen de las creencias es el temor; el temor impide la propia comprensión y opera a modo de pantalla a través de la cual nos miramos a nosotros mismos. Detrás de esa pantalla está una mente repleta de dogmas, afirmaciones y citas que se repiten una y otra vez. Es por eso por lo que Krishnamurti (1975) afirmaba que era preciso tomar consciencia del temor y el miedo que encubren las creencias que habitualmente se han constituido en una forma de escape de la realidad.

Pero para entender la creencia hay que descubrir la razón por la cual la mente se apega a ella, desvelar por qué las creencias han adquirido tanta importancia en la vida, pues pueden estar enmascarando un proceso de evasión. Estudiar las creencias permite conocernos tal cual somos, tomar conciencia de lo que consideramos importante en nuestras vidas, de las cosas que hemos aceptado; nos lleva a conocer cómo funciona nuestro pensamiento al ponerlas en tela de juicio; al observar atentamente el proceso de su desarrollo y someterlas a examen, mostrará las modalidades de nuestro pensamiento y de nuestras reacciones, y revelará los valores y normas que hemos aceptado durante generaciones (Krishnamurti, 1975).

Para emprender la búsqueda, para tener la capacidad de buscar, es indudable que -en primer lugar- debemos comprendernos a nosotros mismos; también es necesario distinguir y darnos cuenta de lo que en realidad buscamos en la vida. Se trata de descubrir lo que uno desea realmente ser, de conseguir por uno mismo qué es lo que busca tan incesantemente para la existencia; en síntesis, antes de empezar a buscar, resulta sin duda importante averiguar quién es el que busca y qué es lo que busca.

Como ya se mencionó líneas arriba, el descontento es la vía de la investigación; pero no puede haber investigación si la mente está atada a la tradición. La investigación es la llama de la atención, mientras que el descontento es un estado puro que existe dentro de nosotros, si no se le apaga a causa de la mala educación. Cuando comprendemos la naturaleza del verdadero descontento, veremos que la atención forma parte de esa llama ardiente que consume la pequeñez y deja a la mente libre de las limitaciones que impulsan la búsqueda de las gratificaciones que la encierran dentro de sí mismo (Krishnamurti, 2007).

Sin embargo -sostiene-, encarar la realidad -tanto interna como externagenera típicamente dos respuestas: desesperación, cinismo y ansiedad o hacerle frente con responsabilidad. Los problemas, desde su percepción, deben afrontarse ahora -en el momento que se toma conciencia de ellos-, a partir de lo cual se produce 
el cambio fundamental de la mente sin la intervención de la voluntad, las influencias y presiones externas, las creencias, las opiniones y la tradición. La necesidad del cambio radical a partir del cual se debe investigar el proceso de conocimiento, cuyo centro es el resultado de todas las experiencias a partir de las cuales actuamos (Krishnamurti, 1999, p. 20).

Conseguir la resolución de un problema de manera inmediata demanda comprender el propio problema; reconocer que el problema crea un conflicto, una contradicción. Es necesario vivir con ese hecho. Lo que a uno le da la capacidad, la fuerza, la vitalidad, el impulso de encarar algo de modo instantáneo con la plenitud de la energía no dividida se pierde porque intervienen diversas razones para no conseguir dicha energía. Una de ellas es que dicho problema -como lo es la vanidad, por decir el ejemplo que plantea Krishnamurti (1975) - está basado en lo que cada quien es, es la base del patrón social que da cierta sensación de vitalidad, cierta condición de dignidad, de distancia con respecto a los demás, el sentimiento de que soy un poco mejor que los otros. Todo eso supone una energía que impide disolver el problema. Si se analizan las razones que han estorbado la acción impidiendo disponer de la energía para encarar el problema -entendiendo el análisis como el proceso que tiene su origen en la repetición, en las reacciones alojadas en la memoria y en la experiencia-, mientras se analiza, el problema prosigue. En cambio, ver el hecho instantáneamente requiere de una mente alerta, incluso cuando no se presentan problemas, para hacerles frente sin pasar por el proceso de análisis.

Es por esa razón por lo que es necesario tener la capacidad de enfrentar las cosas de un modo nuevo, de instante en instante sin la reacción condicionante del pasado para que no haya efecto acumulativo, que obre como barrera entre uno mismo y aquello que se es; es necesario disciplinarse mediante la observación, ser considerados y reflexivos, prestar atención y escuchar para conseguir el orden en el pensar. Para ello es necesaria la libertad, esa que genera autonomía para ser libre de la brutalidad, la ira y la crueldad y que al mismo tiempo depende de la inteligencia, la sensibilidad y la compasión (Krishnamurti, 1975), para generar una conciencia ordenada.

Krishnamurti insistía con frecuencia que la educación debe

ayudar a pensar libremente y sin temor, ayudar a investigar y comprender... [debe ser una educación]... que ayude a ser tan agudamente inteligente que la persona pueda hacer lo que ama... [que despierte]... en su interior la llama del descontento, un estado de revolución [interior]... para inquirir, descubrir y crecer... en madurez y verdadera libertad... (2002, p. 16).

La responsabilidad del educador «... es dar origen a un ser humano bueno que tenga un sentimiento de la relación global, que no sea nacionalista, regionalista, aislado, que no se aferre religiosamente a las viejas tradiciones muertas». Es por eso por lo que pensaba que la educación sólo puede ser transformada educando al educador y no simplemente creando una nueva norma, un nuevo sistema de acción (Krishnamurti, 1974). 


\section{EL DISCURSO PEDAGÓGICO. LA NATURALEZA DEL SABER DE LOS PROFESORES}

En este apartado, se enuncian los aspectos fundamentales que Krishnamurti consideraba que los educadores tenían que saber para ejercer como profesores, tales como: a) cultivar una perspectiva global; b) cultivar la mente científica; c) cultivar la espiritualidad; y desarrollar el cuidado y preocupación por la humanidad y el medio ambiente. Asimismo, se intenta visibilizar la naturaleza del saber de los profesores acerca del desarrollo humano, la reflexión profesional, la enseñanza y el aprendizaje (Jacobo, 2009) que los educadores desarrollan en su cotidianidad escolar, aunque de forma tácita.

Cultivar una visión global. El eduCador en la búsQUeda DE La EXPLICACión Y LA COMPRENSIÓN DEL MUNDO

Para clarificar este saber es necesario que el educador se pregunte ¿¿cómo me observo interiormente? ¿Dónde está el espejo en el que me veo a mí mismo siendo el mundo? ¿Quiero cambiar el mundo? ¿Es necesario cambiarlo? ¿Lo debo hacer individualmente o junto con otros? (Krishnamurti, 1996).

De acuerdo con Krishnamurti (1998), siendo uno mismo el centro de diversas actividades a veces contradictorias, de múltiples pensamientos, sentimientos y deseos que se oponen unos a otros, se debe enfrentar con honestidad esa contradicción psicológica que la humanidad ha cultivado. Todos los seres humanos tenemos un bagaje de conocimientos, prejuicios, experiencias, sufrimientos e innumerables cuestiones complejas que implican la relación -con la naturaleza y los otros-. Cada uno de nosotros es el resultado de una vida culturalmente compleja producto de siglos. Somos responsables no sólo ante el mundo, sino ante nosotros mismos, de lo que hacemos, pensamos y de cómo actuamos, de esa extrańa mezcla contradictoria de violencia y amabilidad, afecto y brutalidad, codicia, celos y ansiedad generadores del caos, la desdicha y la aflicción en el mundo. Cada uno, en sí, es a la vez la sociedad y el individuo, la violencia y la paz, la brutalidad y la ternura. El predominio de unos sobre los otros provoca muchos desequilibrios psicológicos (1998, p. 30); el ser humano es en esencia "la psiquis de la humanidad", es decir, psicológicamente cada persona es el mundo, representa a toda la raza humana y responde al mundo de manera total. Pero también la cultura, las costumbres, los hábitos de una comunidad nos dicen lo que hay que hacer y lo que no hay que hacer.

En contraparte, no se acepta que los individuos sean libres o hagan lo que mejor les parezca; quienes lo intentan son un peligro para la sociedad. La mayoría de la gente no desea que los otros sean libres, pues un hombre libre de verdad -libre de codicia, ambición, envidia, crueldad- es considerado un peligro porque es completamente diferente. Y lo diferente genera desconfianza y temor.

Ello ocurre porque los seres humanos hemos sido programados biológica, intelectual, emocional y psicológicamente a través de millones de años para repetir una y otra vez el patrón del programa. De acuerdo con Krishnamurti (2013), hemos 
cesado de aprender y estamos en riesgo de que la computadora, «que es mucho más capaz, rápida y exacta asuma la dirección de las actividades del cerebro».

En cambio, proponía que nuestros múltiples problemas fueran comprendidos y resueltos tomando conciencia de nosotros mismos como un proceso total, es decir, comprender toda nuestra composición psicológica. Es por ello por lo que pensaba que el profesor debe ser capaz de observar los sucesos mundiales, vigilar sus propias inclinaciones, sus íntimas exigencias y credos (1998, p. 89); debe tener una mente dotada de diligencia que encare los problemas apenas surgen, que observa su naturaleza y los resuelve inmediatamente (Krishnamurti, 2013).

En relación con las acciones a implementar en las escuelas Krishnamurti, es muy importante que el educador, en primer lugar, descubra y se interrogue junto con la comunidad de profesores el por qué él es el mundo y el mundo es él mismo, a partir de la observación y la investigación profunda. Asimismo, en las sesiones con sus estudiantes propiciar ese descubrimiento, a través de la observación y la investigación.

En síntesis, el conocimiento de sí mismo implica a la vez conocer el mundo, es un compromiso con el mundo en interdependencia con el entorno. Uno es el mundo, pero el mundo va en la dirección equivocada, por lo que es necesario cambiar la propia dirección para así contribuir al cambio en el mundo (Vicens, 2001).

\section{Cultivar la mente Científica. El Conocimiento sin elección}

Krishnamurti (1996) pregunta a los profesores ¿̨de qué modo yo, como profesor, emprenderé la transformación psicológica de los estudiantes y además conseguiré que sean capaces y diligentes con sus estudios?

En principio el educador requiere de una mente extraordinariamente flexible y sutil, no ajustable al molde de la sociedad, capaz de investigar y crear una realidad explosiva sin miedo, temor o prejuicio; el educador es un individuo que debe saber todo de sí mismo, de su cuerpo, su mente y sus emociones y de cómo funciona la mente y cómo opera el pensamiento. Para llegar a ello, el educador lo debe hacer con una mente científica que sea aguda, precisa, clara y sin prejuicios (1978).

Krishnamurti (1978) clasifica el conocimiento en tres tipos: científico, colectivo y personal. El conocimiento científico es el que se enseña en las escuelas; el conocimiento colectivo es producto de la experiencia importante de las generaciones pasadas y que se expresa en las tradiciones de la comunidad y la raza; el conocimiento personal procede de las propias experiencias, reacciones, impresiones, inclinaciones y tendencias. Todos esos conocimientos entran en juego en el contexto de los centros escolares.

En cuanto al conocimiento científico que debe cultivarse en la escuela, Krishnamurit (1992) afirmaba que

... necesitamos el conocimiento para poder comunicarnos, para decirnos algo el uno al otro; y para cultivar el conocimiento tiene que haber memoria. Sin el conocimiento no podríamos hacer volar un avión, ni construir un puente o una casa hermosa, no podríamos construir grandes carreteras, cuidar de los árboles, de 
los animales, y hacer tantas cosas que un hombre civilizado tiene que hacer. Para generar electricidad, para trabajar en las distintas especialidades científicas, para ayudar al hombre mediante la medicina, etc., para todo esto nos hace falta tener conocimientos, información, memoria, y en estas cuestiones es necesario recibir la mejor instrucción posible. "Por eso es muy importante que, técnicamente, tengan ustedes maestros de primera clase que les trasmitan la información apropiada y los ayuden a cultivar un conocimiento cabal de las diversas materias...».

Para él era particularmente necesario utilizar el conocimiento en beneficio del hombre. Pero en la escuela el conocimiento se trata desde el punto de vista de la tradición, convirtiéndose en un obstáculo. Es aquel conocimiento relacionado con las creencias, que moldean y condicionan la mente a un patrón particular. Por lo que es necesario replantearse el propósito de la educación: «Dar al que estudia un conocimiento abundante sobre los diversos campos del esfuerzo humano" y al mismo tiempo liberar a la mente de toda tradición para que sea capaz de investigar y descubrir.

En el proceso de impartir conocimiento, el educador debe invitar a la discusión y alentar a los estudiantes para que investiguen y piensen de manera independiente. El educador y el estudiante están ambos aprendiendo a través de la especial relación mutua que han establecido (2013). Es responsabilidad del estudiante exigir, preguntar y no simplemente esperar a ser enseńado. Es importante que en la clase se discuta "cómo leer, cómo aprender, qué significa prestar atención» (1978).

Por lo tanto, la intervención del educador debe favorecer el orden en el pensar y el cultivo de la inteligencia. Cultivar la inteligencia significa desarrollar la capacidad para la comprensión directa y aprender a utilizar el conocimiento con responsabilidad moral.

Krishnamurti (2013) afirmaba que cada profesión exige aprender sobre ella lo más posible. Consiste en acumular conocimientos al respecto y actuar con toda la destreza posible. La profesión del educador no podía ser la excepción. Pensaba que había dos maneras de aprender esos conocimientos, una deductiva y la otra inductiva. La primera de ellas consistía en adquirir una gran cantidad de conocimientos mediante estudios y después actuar a partir de ese conocimiento; la segunda consiste en actuar, hacer algo y aprender mediante la acción; uno y otro se basan en el conocimiento y en la experiencia, pero ambos son siempre limitados. Pensaba en cambio que tanto el educador como el educando deben descubrir qué es realmente aprender. La observación de sí mismo - de los prejuicios, las creencias, las sutilezas del pensamiento, su vulgaridad, su insensibilidad- en la que se desarrolla la comprensión de sí y del otro convierte al educador al mismo tiempo en maestro y discípulo. Cuando educador y educando están aprendiendo no existe el educador ni uno que deba ser educado, sólo existe el aprender y el aprender da origen a la igualdad entre los seres humanos.

Krishnamurti (2007) insistía en que el conocimiento es necesario como un medio para cultivar la mente y no como un fin en sí mismo. Es por eso por lo que el ser humano, afirmaba, debe cultivar la mente científica y la espiritualidad; la mente científica se basa en el descubrimiento, deduce conclusiones, edifica teorías, 
se mueve de hecho en hecho; la espiritualidad, en cambio, no se aferra a ningún tipo de creencias o dogmas, por lo que una de las tareas fundamentales de la educación es descubrir las áreas donde el conocimiento y la destreza técnica son necesarios y dónde son improcedentes y hasta dañinos. La escuela no sólo debe impartir conocimiento sino despertar la inteligencia para saber cómo utilizar el conocimiento, cultivar la capacidad para discernir; es decir, la percepción instantánea desde la cual surge la acción, la inteligencia que utiliza el pensamiento como una herramienta y que no deja la cicatriz del recuerdo, que no es una actividad mecánica.

Krishnamurti plantea la noción esencial de dudar de todo, incluido el conocimiento y el propio pensamiento, insistía en el escepticismo hacia el conocimiento de uno mismo porque afecta a todos los demás conocimientos, porque cuando el pensamiento se imagina que lo sabe, imaginándose al mismo tiempo como un individuo que sabe, todo lo que ve es la proyección de sí mismo. No está escuchando o aprendiendo sino reduciendo la espontaneidad de la vida a la identificación. Cuando creo que sé, todo lo que puedo percibir es en realidad una extensión hermética de mi viejo pensamiento que se repite (Clarin, 2013) recursivamente.

\section{Cultivar la espiritualidad. Aprender a Ser uno mismo en Un MUNDO en CaOS}

¿Puede el educador comunicar el sutil y complejo problema del conflicto en los seres humanos? ¿Tiene la energía de la inteligencia para desarmar las cosas que los seres humanos han armado psicológicamente en torno a sí mismos? ¿Cómo ha de ayudar el educador para que el estudiante enfrente todo eso? Son las cuestiones que Krishnamurti (2013) conversa con los profesores en sus charlas y en sus cartas a las escuelas.

Para él, la búsqueda espiritual es la búsqueda de orden en la conciencia del hombre. En este sentido, el educador debe ayudar a los alumnos a descubrir cómo es que han llegado a ser lo que son; investigar conscientemente los diversos fragmentos que componen el "yo», el contenido de la consciencia que forma parte de la cultura en la que cada quien ha sido educado, puesto que son acciones que la mente inconsciente absorbe de manera constante y tienen un efecto mayor en los individuos. Es por ello por lo que la mente debe indagar en su contenido, descubrir las divisiones, la agresividad, para cambiar la estructura de la conciencia y conectarlos entre sí, ver si puede cesar esa fragmentación y esa fragmentación cesa cuando se comprende que nuestra conciencia está compuesta de todos esos fragmentos. Asimismo, descubrir, explorar hasta la raíz por qué aceptamos las creencias, la tradición; comprender los motivos, las causas de esa aceptación. Tales creencias-religiosas, políticas y de todo tipo- separan a los hombres y crean conflicto, confusión y antagonismo generando la intolerancia.

Una mente que funda sus raíces en el temor -afirmaba- no puede pensar con rectitud, con lógica, con cordura, con salud. El temor impide el florecimiento de la mente y de la bondad. Cuando se aprende por medio del temor-cuya base es la autoridad-se imprime en el cerebro la necesidad de obedecer y entonces se deja de pensar, se doblega y se convierte a la mente en esclava de una idea, de una impre- 
sión mental, de una influencia, y se deja de aprender. La actitud autoritaria destruye toda inteligencia y el sentido de obediencia engendra temor que en sí mismo aleja inevitablemente la comprensión de la verdadera naturaleza de la inteligencia. La obediencia, el seguimiento, la aceptación ciega o consciente de la autoridad debe inevitablemente producir desorden; cuando uno vive en el desorden (psicológico) la sociedad se vuelve caótica y eso es lo que crea autoridad; entonces todo ser humano contribuye a crear autoridad, a través de la «necesidad» de obtener orientación.

Krishnamurti pensaba que el maestro tiene una responsabilidad mucho mayor que comunicar y trasmitir informaciones, ideas, teorías; debe interesarse en la conducta, en la complejidad de la acción humana, en un estilo de vida que implique el florecimiento de la bondad. Afirmaba en sus Cartas a las escuelas (2013) que el estudiante llega a la escuela desde un ambiente de miedo, de autoridad; con toda clase de impresiones y apremios reales o imaginarios. Del mismo modo, el educador también tiene sus propios temores y tensiones; no será capaz de producir la comprensión de la naturaleza del temor si él mismo no ha descubierto la raíz de sus propios temores. Además, hay que enfrentar un mundo que se está desintegrando y degenera rápidamente; en el que no hay sentido alguno de moralidad, donde nada es sagrado, donde nadie respeta a nadie, pues a pesar de todos estos millones de años de evolución del hombre, el mundo se ha vuelto violento, insensible y destructivo.

En este sentido, afirmaba que la función de la educación consiste en ayudar a los nińos a no imitar a nadie, a ser ellos mismos todo el tiempo, a encontrar la comprensión de la libertad de «instante en instante», porque para él, el principio y el fin de la educación es la comprensión de sí mismo para comprender la vida (1992).

Sostenía que la experiencia lo que hace es fortalecer la mente condicionada de quien la experimenta, perpetuando el hábito y la rutina que conducen a un modo mecánico de vivir. El hábito es una acción reiterativa del no estar atento, que coloca a la mente dentro de un surco, de un estrecho modo de vida. Caemos en el hábito porque es el modo más cómodo de vivir y cuando se observa detenidamente, se descubre que el hábito en la relación encubre cierta indolencia, negligencia y descuido lo que vuelve a la mente insensible, conduciéndola a un proceso degenerativo que tiene por objeto alguna forma ilusoria de seguridad a la cual aferrarnos (2013).

Es por eso por lo que el educador debe enseñar en contra de los antiguos métodos, pensar de un modo totalmente diferente respecto a la enseñanza, la libertad y el orden; se hace necesario que el profesor observe detenidamente las acciones, los comportamientos, los gestos y las actitudes cotidianas que se dan en la relación con los estudiantes y comprender esta estructura de conocer para saber despertar la inteligencia. Por esa razón, el profesor debe investigar la naturaleza destructiva de la tradición y de los reiterativos procesos del pensamiento que se trasmiten a través de los rituales, las palabras y las creencias que carecen de sentido pero que la emoción, el sentimiento, el romanticismo y la imaginación le proporcionan color e ilusión que generan un desperdicio de energía que degenera la mente (2013).

En cambio, la relación entre profesor y estudiante debe darse en 
... una conversación entre dos personas, entre usted y el que habla, no sobre un tema en particular, instruyendo y dando forma a su pensamiento u opiniones. Somos dos amigos sentados en un banco, discutiendo nuestros problemas, amigos que están profundamente preocupados por lo que está pasando en el mundo, con la confusión, el caos que existe en todo el mundo. Me pregunto si tiene un amigo con el que hable, a quien expone sus propios sentimientos, conceptos, ideas, desilusión, etc. Vamos a hablar juntos de esa manera: explorando, indagando, sin prejuicios, en gran amistad, lo que significa con gran afecto, respetándonos unos a otros, sin tener algún tipo de pensamiento oculto, motivos ocultos (Krishnamurti, 2003).

\section{EL CUIDADO Y PREOCUPACIÓN POR LA HUMANIDAD Y EL MEDIO AMBIENTE. APRENDER A CONVIVIR MÁS ALLÁ DE LAS JERARQUÍAS}

Tradicionalmente, dice Krishnamurti, la relación entre educando y educador ha sido jerárquica, haciendo sentir al estudiante inferior; esta relación le hace vivir con un sentimiento de tensión y de fatiga haciéndole aprender una condición que le hace sentirse empequeñecido, volverse agresor y continuamente acomodaticio y servil. Hasta ahora la educación ha cultivado la competencia y alimentado el conflicto. La educación se ha vuelto un verter de múltiples materiales en nuestro cerebro que nos condiciona a ajustarnos. La educación, tal como la conocemos ahora, consiste en afrontar una monótona y estrecha existencia sin sentido (2013).

Es por eso por lo que en las escuelas Krishnamurti (2013) los participantes en los centros educativos son simplemente el personal y los estudiantes. El personal, sin importar su función, se encuentra en la posición de educador. No existe una jerarquía verdadera entre ellos, más que las diferencias en responsabilidades y experiencias. En cuanto a las preocupaciones centrales de la educación que tienen que ver con la libertad interior, tanto estudiantes como profesores son alumnos. La escuela se entiende como una comunidad que actúa con libertad, lo que significa que hay una relación no autoritaria entre sus integrantes, quienes son diferentes tipos de personas, con diferentes temperamentos y características intelectuales.

La educación debe ser un medio para descubrir nuestra verdadera relación con las cosas, con otros seres humanos y con la naturaleza. Por esa razón, el educador debe aprender a estar en comunión con la naturaleza para que su relación con los otros seres humanos sea sencilla, clara y libre de conflictos (2007).

Del mismo modo, las escuelas deben generar empatía hacia otros seres humanos que sufren, luchan, experimentan la gran angustia y el dolor de la pobreza, pero también de quienes, teniendo lujos y riquezas, sufren la competencia, la envidia y la necesidad de cubrir las expectativas de los demás.

Sugería que cuando el educador se interesa en esto, está ayudando al estudiante a que se vuelva sensible a los sufrimientos de otras personas, a sus luchas, ansiedades y preocupaciones y a las disputas que ocurren en la propia familia. En ese sentido el educador debe educar a los niños y a los estudiantes para que estén en comunión con el mundo porque el mundo está donde está el estudiante, ese es 
su mundo. Esto debería traer consigo una natural consideración, un natural afecto y cortesía hacia los demás y una conducta que jamás es ruda, cruel y vulgar. En sus Cartas a las escuelas (2013) insiste:

... el educador debe hablar de todas estas cosas, no solo verbalmente, sino que él mismo debe sentirlas -sentir el mundo, el mundo de la naturaleza y el mundo del hombre-ambos están relacionados entre sí... el hombre no puede escapar de ello. Cuando destruye la naturaleza se está destruyendo a sí mismo. Cuando mata a otro ser humano se está matando a sí mismo. El enemigo no es el otro sino uno mismo. Vivir en armonía con la naturaleza, con el mundo, da origen a un mundo distinto...

Para establecer una relación con la humanidad y con todo lo que vive y muere sobre la tierra, las escuelas deben estar rodeadas de la naturaleza, deben tener sitios especiales para el silencio para cultivar una mente tranquila en los que los participantes tengan oportunidad de observar sus propios pensamientos (Cartas a las escuelas, 2013). Al mismo tiempo la vida en las escuelas Krishnamurti debe entenderse dentro de la convivencia, porque nada ni nadie puede existir en el aislamiento. Porque la convivencia sólo tiene verdadera significación cuando ocurre un proceso de autodescubrimiento (Krishnamurti, 2013). Habitualmente la vida de relación transcurre sin gran significación en la convivencia; pero en la vida diaria nos servimos de ella como medio para ocultar nuestra propia insuficiencia, nuestras propias dificultades, nuestras incertidumbres.

En la convivencia de los centros escolares, el afecto debe funcionar como una bisagra que moviliza la relación; Krishnamurti pensaba que cuando el afecto está de por medio, es más fácil eliminar los malentendidos, conversar sobre ellos y olvidarlos sin el riesgo de ser acumulados. El afecto significa moverse hacia alguien o ser afectado por algo. El afecto emerge en la relación para crear esa atmósfera en la que puede funcionar una comunidad escolar, entendida como el hogar en el que se da origen a la responsabilidad y la participación en su construcción. En ese sentido, la escuela debe ser afectuosa, debe ser el sitio donde hay cierta libertad y un sentimiento de hallarse seguro, bien provisto y protegido. El estudiante debe sentir que se encuentra en su propia casa, donde hay personas que se ocupan de sus gustos, del modo en que habla, que es cuidado tanto física como psicológicamente; el lugar en el que le ayudan a liberarse de sus heridas internas y sus miedos, en el que se crea la atmósfera en la que tanto educadores como estudiantes estén floreciendo en la bondad. El profesor, por su parte, debe estar atento a las imágenes que la sociedad y los padres han impuesto en el estudiante o a las que el mismo estudiante ha creado. Entonces la función de la escuela consiste en ayudar al estudiante a despertar la inteligencia, aprender la importancia de la verdadera relación y comprender la naturaleza del temor generado por las relaciones jerárquicas que ha experimentado tanto en la sociedad como en la escuela (2007).

En congruencia con lo planteado, el educador debe saber cómo ayudar al estudiante a usar las palabras, la inteligencia y el amor, ayudarlo a comprender hasta qué punto es influido y moldeado para ajustarse al patrón de la sociedad; ayudarlo a liberarse de toda clase de influencias de modo que vea por sí mismo cuál es 
la acción correcta para que pueda enfrentarse inteligentemente a la vida con todas sus complejidades.

Por el bien de los estudiantes, el educador y los padres deben aprender el arte de trabajar juntos, con tal de no generar incongruencias y contradicciones en la atmósfera generada tanto en la escuela como en el hogar; habitualmente, acostumbramos trabajar juntos según las líneas de una autoridad establecida, en torno a un individuo carismático para desarrollar un concepto o promover un ideal mediante la persuasión y la propaganda. En cambio, en los centros Krishnamurti, la relación entre individuos alertas y vitales debería generar recursivamente acciones de cooperación entre la familia y la escuela.

También es necesario que el personal de los centros escolares sea sensible al medio ambiente. Es por eso por lo que, estratégicamente, las escuelas Krishnamurti se ubican en entornos rurales, que contribuyen a fortalecer las economías de las comunidades cercanas, pues las escuelas participan en programas de revitalización ecológica tanto como en las asignaturas de matemáticas, artes, ciencias sociales o lenguas. Educación ecológica, compromiso social y árboles van juntos con la conciencia, el respeto y la libertad (Vicens, 2001).

\section{DESARROLLO HUMANO COMPLEJO}

El desarrollo se explica por la interacción de factores que tienen su origen tanto en el ambiente como en lo que la persona tiene de suyo (Jacobo, 2006, 2009).

En este sentido, para Krishnamurti, el cuerpo, las emociones y la mente componen al ser humano total. A menos que vivan armoniosamente, el conflicto es inevitable (1993). Es necesario mantener el cuerpo con vitalidad y salud para el completo desarrollo de la persona; pensaba que los impulsos emocionales son un medio más potente que cualquier razonamiento intelectual, por lo tanto debemos ser sensibles a todo lo que nos rodea y explicitar nuestras emociones, pues en ellas reside la respuesta «no calculada que generosa constituye la verdadera moralidad y la conducta»; el desarrollo intelectual alude al particular proceso de la mente del cual dependerá que partamos de los hechos y no de las creencias heredadas de la tradición.

Krishnamurti (1978) afirmaba que los adultos ejercen toda forma de control sobre los niños para hacerlos encajar dentro del surco, dentro de un armazón, de un patrón; eso era posible porque «la mente del niño es como una masilla o greda, y esa masilla es impresa como los surcos de una grabación. Todo se registra. De modo que el niño registrará todo consciente o inconscientemente» hasta convertirse en un ser condicionado. Ante ello, proponía que la educación buscara el desarrollo total del ser humano y ayudarlo a realizar su más alta capacidad. El pleno desarrollo de todos los individuos crea una sociedad de iguales, es lo que persigue la correcta educación. Cualquier comparación que se establezca entre los individuos impide su florecimiento pleno. Cuando un individuo está floreciendo a su más plena capacidad no hay comparación, sólo existe la expresión de la capacidad en el campo o profesión en el que se desarrolle (2002). 
Congruente con ello, pensaba que no es tarea del educador comparar las capacidades de sus estudiantes, sino apoyarlos para descubrir sus propias aptitudes. Incluso, antes de que el estudiante elija sus materias se le debe orientar hacia un proceso de descubrimiento de sí mismo, cultivar sus capacidades innatas, para que se incline no por las materias más fáciles sino por aquellas por las que puede expresar sus capacidades hasta su más pleno y alto nivel (2002).

En cuanto a los procesos de desarrollo de los alumnos, los concebía como seres humanos en armonía consigo mismos y con el entorno, con posibilidades de desarrollarse a su más alta capacidad, lo cual el educador debe favorecer al mismo tiempo que mantenerse a la expectativa sobre toda clase de influencias e impresiones cuyo efecto poderoso conduzca al conformismo (Krishnamurti, 1975, 52). Por eso es esencial luchar con el ambiente de cada quien, comprenderlo y abrirse paso por él (Krishnamurti, 1983). Es sólo a través del conflicto y la comprensión del mismo que hay integración. La integración implica la completa unificación de nuestro ser en todo lo que hacemos, decimos y pensamos. Sólo así es posible comprender la relación que uno tiene con la sociedad. Para lograr la integración es esencial la rebelión, cuestionar los valores establecidos por la tradición.

\section{ENSEÑANZA MULTIPROCEDIMENTAL Y APRENDIZAJE POR DESCUBRIMIENTO}

La enseñanza es un concepto clave en las ideas pedagógicas de Krishnamurti (2018), para quien el profesor debe «descubrir cómo ayudar al niño que no es brillante sin que tenga que competir con el primero de la clase... descubrir cómo enseñar a todos los niños» (p. 36). Afirmaba que no quería que los niños «se sien$\tan$ superiores o inferiores», por lo que el profesor debe «descubrir una forma de no herir a... los... niños». El pensamiento del profesor, decía, debe experimentar una revolución para producir una respuesta nueva; sostenía que «el maestro debe conocer las habilidades de los niños y guardar un registro» de las mismas, «ayudar al niño desde donde está y no desde donde debería estar». La satisfacción del profesor no debe limitarse a ayudar al niño a aprobar exámenes. Debe poder generar un ambiente en el que el niño tenga confianza para hablar y consultar dudas en libertad y de forma directa, en ausencia de jerarquías y contradicciones, lo cual supone despertar la iniciativa del niño mediante la meditación, la investigación y la disciplina. Esta última, la disciplina, quiere decir «el discípulo que aprende del maestro» (Krishnamurti, 1985), por lo que la disciplina no implica represión, control, amoldamiento o ajuste a una ideología.

En consonancia con lo anterior, el aprender es un proceso de no acumular conocimientos, de observar sin el conocimiento acumulado, observar la vida cotidiana y la actividad de la mente sin ninguna conclusión (Krishnamurti, 1996a). Por lo tanto, la educación es el acto de aprender, no sólo de los libros sino de todo el movimiento de la propia vida; significa aprender acerca de la naturaleza del intelecto y del pensamiento que opera al intelecto. Consideraba que, aunque el aprender de los libros es importante, es mucho más importante aprender del libro que 
cuenta la historia propia, puesto que cada uno de nosotros representa a la humanidad entera (Krishnamurti, 2013).

Afirmaba que

... el libro no está ni ahí afuera ni oculto dentro de usted. Está a su alrededor. Usted forma parte de ese libro. El libro le cuenta la historia del ser humano y tiene que leerlo en sus relaciones, reacciones, conceptos y valores. El libro es el mismísimo centro de su ser y el aprendizaje consiste en leer ese libro con exquisito cuidado. El libro le cuenta la historia del pasado, cómo el pasado conforma su mente, su corazón y sus sentidos... (2013, p. 116).

Por lo que aprender significa escuchar no sólo con el intelecto sino con el corazón. Es decir, con afecto, objetividad y cordura, suspendiendo las creencias, opiniones y razones. Aprender requiere de la observación pura, tanto interna como externa. El aprendizaje desaparece cuando aparece el maestro; aprender desde el conocimiento de uno mismo es saber cómo escuchar, cómo observar (1992). Tanto el educador como el educando han de descubrir qué es realmente aprender. Cuando educador y educando están aprendiendo no existe el educador ni uno que deba ser educado, sólo existe el aprender y el aprender origina igualdad entre los seres humanos.

De acuerdo con Krishnamurti, el aprender sólo ocurre cuando no hay presión; pues cuando se aprende bajo presión se cultiva la memoria y se obtienen respuestas mecánicas. En este sentido, la función del maestro es la de educar la totalidad de la mente, de modo que los estudiantes no queden atrapados en el pequeño remolino de la existencia. Por lo tanto, la finalidad de la educación debe estar orientada a eliminar el temor, puesto que cuando hay temor no se puede aprender sino sólo adquirir conocimientos de manera mecánica. El temor está involucrado con la competencia y en la raíz de la competencia está el miedo a no ser nadie. Aprender sin temor constituye un problema complejo que implica la eliminación de toda competencia. En el proceso de competir todos se someten, se ajustan y destruyen la sutileza del cerebro. La correcta educación cultiva al ser total, dando profundidad y comprensión de la belleza tanto a la mente como al corazón.

\section{LA REFLEXIÓN PROFESIONAL DEL EDUCADOR}

Krishnamurti aseguraba que los profesores deberían reflexionar juntos lo que hacen tanto en el aula como fuera de ella, intercambiar pareceres y corregirse mutuamente. Los profesores con más años en la escuela deben asegurarse de que los profesores principiantes comprendan lo que se está haciendo en las escuelas Krishnamurti (2013). Afirmaba que el profesor es un sujeto reflexivo y sensible, mientras que el alumno es un sujeto activo que pregunta libre de prejuicios. La reflexión consiste en el observar atenta y profundamente sin juzgar, sin la presencia de prejuicios como prerrequisito para el aprender.

Un aspirante a ser profesor de los centros Krishnamurti debe permanecer por algún tiempo en ellos para vivir un proceso de socialización e inmersión que le 
permita descubrir si puede incorporarse con alegría a lo que se está haciendo y que se sienta seguro y contento como si estuviera en casa (Krishnamurti, 2013). Todo lo cual debe ocurrir en un entorno seguro y confiable -no un ambiente basado en el miedo, la recompensa, el castigo y la autoridad-, para tener una visión profunda de nuestras vidas y de los patrones psicológicos que le acompañan, lo cual conlleva la posibilidad de un cambio radical que las prescripciones morales, las reglas y los castigos simplemente no lo hacen (Onkar, 2012).

El maestro, decía Krishnamurti (2013) en sus Cartas a las escuelas, deberá formarse en contra de los antiguos métodos. Viéndose privado de ellos se enfrentará a un problema que tendrá que pensar de un modo completamente diferente. Para lograrlo, es necesario olvidar los viejos patrones del pensar con respecto a la enseñanza, la libertad y el orden; la mente debe ser libre de mirar y examinar la cuestión de la libertad y el orden para estar en contacto con el hecho real y comprender la libertad y reconocer e identificar a los viejos métodos como destructivos (Krishnamurti, 1998).

Aunque Krishnamurti no hizo explícita alguna teoría de las ciencias de la educación para aplicar a la reflexión profesional (Jacobo, 2009), consideraba que el profesor debe tener un conocimiento profundo de sus estudiantes tanto como de sí mismo y cultivar la inteligencia y la sensibilidad propias para generarlas en sus alumnos, para comunicarles ese sentido de indagación en el pensar. Sostenía que el educador debe tener los conocimientos necesarios con los cuales poder comunicarse con sus estudiantes, debe ser técnicamente un experto del contenido de su materia, además de crear un sentimiento, una atmósfera en la que ambos - profesor y estudiante- quieran descubrir, en la que el que enseña y el enseñado tienen ambos urgencia de aprender y enseñar.

La reflexión social remite al compromiso moral y ético del educador con respecto a la formación del futuro ciudadano (Jacobo, 2009). En este aspecto, Krishnamurti pensaba que el educador debe comprender el significado de la educación y tener una respuesta completa a la totalidad del problema. Para ello, el educador debe conocer las influencias que ejercen la familia y la sociedad en su estudiante para comprenderlo y saber cómo ha de intervenir en su interioridad para lograr alcanzar lo que cada uno desea ser. Por esa razón el educador debe tener una visión global al mismo tiempo que un conocimiento profundo acerca de la sociedad y de la familia. Saber cómo se reproducen los pensamientos, sentimientos y comportamientos de los seres humanos en sus interacciones diarias para sostener el orden de cosas existentes.

Krishnamurti nos dice que es necesaria una cultura nueva porque «la vieja cultura ya está muerta, consumida, sepultada, hecha trizas, vaporizada» (1999, p. 50). El futuro ciudadano debe crear una cultura nueva libre de crueldad y de violencia que no contribuya a la existencia de un mundo destructivo como el actual. Una cultura nueva en la que existe el amor, la caridad, la generosidad y el afecto. El futuro ciudadano debe escoger desde hoy reflexivamente entre seguir el camino de la violencia o enfrentarse a la sociedad. Para lograr ese cambio radical, es necesario estudiar todo el proceso de destrucción y desorden tanto en el entorno como dentro de sí mismo para lograr hacer emerger un orden por completo diferente, no 
como una casa que deba ser demolida para poner otra en su lugar sino mediante la educación que produce el cambio del hombre interior...

Debo conocerme a mí mismo tal como soy, no como pienso que debería ser. Debo conocerme como el centro desde el cual actúo y pienso, el centro que se compone de conocimientos acumulados, suposiciones, experiencias pasadas, todas esas cosas que impiden una revolución interna, una radical transformación propia. Y como en el mundo actual tenemos tantas complejidades y ocurren tantos cambios superficiales, es indispensable que exista este cambio radical en el individuo porque solo el individuo y no lo colectivo puede dar origen a un mundo nuevo (1999, p. 21).

El diseño de lo humano, por lo tanto, deberá ir en contra del amoldamiento para encajar en la sociedad y de la adaptación dentro de la corriente de actividad social y económica. Para lograrlo es necesario - parafraseando a Krishnamurticonstruir una clase correcta de educación que oriente a las mentes para soportar las tentaciones, las influencias y la bestialidad de la civilización y la cultura actuales; lo que se pretende es una educación que conduzca a crear una cultura basada en la verdadera espiritualidad, lo cual implica que el educador debe descubrir lo que toda existencia significa, ser moralmente íntegro, hacer entrar en acción su inteligencia, no valerse de la enseñanza para adquirir posición, poder, autoridad, ni exigir nada para sí mismo, estar más allá y por encima de la sociedad y no estar bajo el control de los gobiernos, ser libres de toda coacción para que les sea posible crear una nueva cultura, una nueva estructura, una nueva civilización (1974).

Es por ello por lo que el educador debe consagrar su pensamiento, su esmero y su afecto en crear el ambiente apropiado, la atmósfera conveniente para que cuando el niño crezca y alcance la madurez sea capaz de habérselas con cualquier problema humano que se plantee (1972). Y eso sólo se logra en el convivir diario, en las interacciones afectuosas entre los participantes en la comunidad escolar.

En síntesis, para lograr la buena sociedad, Krishnamurti sostiene que el cambio no puede proceder de medios externos sino de «un descubrimiento interior que debía trascender la materialidad del cuerpo y originar una mutación en la mente humana», de una transformación total de la conciencia que no requiere de prácticas de tipo mecánico ni de adhesión a ningún dogma, sino una mirada crítica y un conocimiento sin elección, como forma de autodescubrimiento (Tapan, 2001). En síntesis, se puede decir que está implícita en su discurso una reflexión profesional del tipo sociocrítico (Jacobo, 2009), pues pretende el cambio radical de la persona para lograr el cambio radical de la sociedad.

\section{CÓMO Y DÓNDE FORMAR A LOS EDUCADORES. UNA REFLEXIÓN DESDE LAS EXPERIENCIAS DE LAS ESCUELAS KRISHNAMURTI}

Las experiencias documentadas en el Journal of the Krishnamurti Schools representan acciones, presumiblemente, que van en la dirección que orientaba Krishnamurti. Por ejemplo, de tales acciones han surgido conceptos como la «pedagogía del vacío", "currículum en espiral»; asimismo se han documentado experiencias 
de enseñanza de las matemáticas y de la clase de escritura de ensayos, también se han desarrollado esfuerzos por clarificar lo que significa «cultivar la mente científica» y la "espiritualidad", cómo traducir a la práctica al enseñar al mismo tiempo un contenido mientras que el estudiante reflexiona sobre sí mismo, lo cual representa para los educadores un enorme desafío, una gran responsabilidad y compromiso ético y moral.

Se dice que es necesario visualizar un programa de formación docente en sí mismo como un crisol para la investigación, donde los docentes participan y se sumergen en un proceso de descubrimiento y redescubrimiento, por sí mismos, sobre la naturaleza de la enseñanza y el aprendizaje (Krishnamurthy, Lommel \& Clark, 2010). En este sentido, Krishnamurti (2018) pensaba que los profesores juntos deben contribuir con sus inteligencias con toda la intención de despertar un sentimiento de confianza y seguridad que facilite la cooperación para lograr la transformación de las escuelas.

Para efectos de obtener una aproximación a la comprensión de la propuesta formativa en el modelo pedagógico de Krishnamurti, acudiremos a un ejemplo desarrollado dentro del proyecto School-in-the-box de la escuela de Rishi Valley de la India.

Krishnamurthy, Lommel y Clark (2010) documentan una experiencia desarrollada en Ojai, California, en la que los participantes -educadores de diferentes centros escolares Krishnamurti- reflexionan sus propios cronogramas -o líneas del tiempo- educativos y determinan las pautas de inflexión en sus propias educaciones. Trabajan en torno a sus afirmaciones sobre el aprendizaje para generar objetivos de la educación; las afirmaciones son frases que ha dicho Krishnamurti, tales como "descubrir lo que aman hacer", "crear libertad en el individuo", etcétera. Luego, inspirados en la película La escuela sin muros del proyecto School-in-the-box fundado en Rishi Valley, cada profesor intenta un diseño esquemático de su propia escuela o aula en una caja, descubriendo o elaborando diez componentes que reflejan directamente su intención de educar. En parejas, se cuestionan duramente sobre sus intenciones. Por otra parte, evalúan, con una nueva visión, los problemas persistentes en las escuelas y las respuestas convencionales a dichos problemas contra las respuestas correspondientes proporcionadas por su diseño de escuela. Observan críticamente el origen de los problemas y la eficacia de las respuestas estándar. Colectivamente, incluyen todos sus objetivos individuales en una sola declaración de intenciones para la educación. Esta actividad de articular de forma conjunta sus intenciones educativas sirvió para desarraigar sus supuestos y reveló su compromiso educativo. De ese modo, la brecha entre sus ideales y sus modos reales de enseñanza y aprendizaje se visibilizaron.

Surgen de ahí algunas interrogantes, tales como ¿cómo es un entorno de aprendizaje que no está dirigido por un método? Si aceptamos que el aprendizaje académico no se puede medir, ¿cuál es la medida de la excelencia académica? ¿Puedo, como docente, hacer preguntas a mis alumnos sobre las cuales no conozco su respuesta? 


\section{EL DISCURSO PEDAGÓGICO DE JIDDU KRISHNAMURTI EN CONTRASTE CON EL PERFIL, PARÁMETROS E INDICADORES DEL DESEMPEÑO PROFESIONAL DOCENTE EN MÉXICO}

¿Cuáles son las ideas de Krishnamurti que se pueden evidenciar en el perfil, parámetros e indicadores de los profesores de educación básica?

La ley general del servicio profesional docente en México ha determinado una definición de las capacidades básicas del aspirante a los concursos de oposición para el ingreso a los puestos del sistema educativo mexicano. Para ello ha establecido el PPI (perfil, parámetros e indicadores), en el cual los perfiles pueden ser percibidos como «marcos de referencia para definir conocimientos, habilidades y actitudes deseadas en los actores educativos» (Ingvarson y Kleinhenz, 2006, citado en Cordero, 2015). Los perfiles se organizan en cinco dimensiones con un número variable de parámetros e indicadores. Las dimensiones del PPI se pueden ver en la figura 1. Para una versión más amplia en la que se incluyen los parámetros e indicadores, revisar http://servicioprofesionaldocente.sep.gob.mx/portal-docente-2014-2018/content/ba/docs/2017/ingreso/PPI_INGRESO_EB_2017_2018.pdf.

En la primera dimensión se dice que "un docente que conoce a sus alumnos, sabe cómo aprenden y lo que deben aprender». De esta primera dimensión, se puede decir que en el discurso pedagógico de Krishnamurti se encuentran algunos parámetros e indicadores más o menos presentes; no se puede saber si en la intención y significado con el cual lo decía Krishnamurti, pero haciendo un esfuerzo de relacionarlos se puede decir que el indicador 1.1.3., que a la letra dice «Identifica las características del entorno familiar, social y cultural de sus alumnos para poner en práctica su intervención docente», es una preocupación central en las escuelas Krishnamurti. Pensaba que el profesor debe estar atento a las imágenes que la sociedad y los padres han impuesto en el estudiante o las que él mismo ha creado para ayudarle a despertar la inteligencia y comprender la naturaleza del temor generado por las relaciones jerárquicas. Este conocimiento preparaba al profesor para la intervención docente y propiamente de los contenidos.

No fue posible encontrar, en cambio, alguna alusión a los enfoques didácticos o los contenidos de aprendizaje específicos referidos en los demás indicadores de la primera dimensión, conocimientos que consideraba que los profesores debían poseer como profesionales de la educación. Aunque en los artículos documentados en el Journal se asoman algunos ejemplares para la intervención didáctica, los cuales se han asociado al constructivismo. La estrategia educativa principal está enfocada en la conversación, en la que el educador debe invitar a la discusión y alentar a los estudiantes para que investiguen y piensen de manera independiente. Consideraba importante el modo en que se enseña, pues el educador debe favorecer el orden en el pensar y el cultivo de la inteligencia en la búsqueda de la verdad. Enfatizaba en la responsabilidad del educador de interesarse en la conducta, en la complejidad de la acción humana, en un estilo de vida que implique el florecimiento de la bondad, lo que más o menos se puede relacionar con la segunda dimensión en el parámetro 2.4, en el que se afirma que el educador «construye ambientes favorables para el aprendizaje», en los indicadores 2.4.2. y 2.4.3. «Desarrolla acciones basadas 


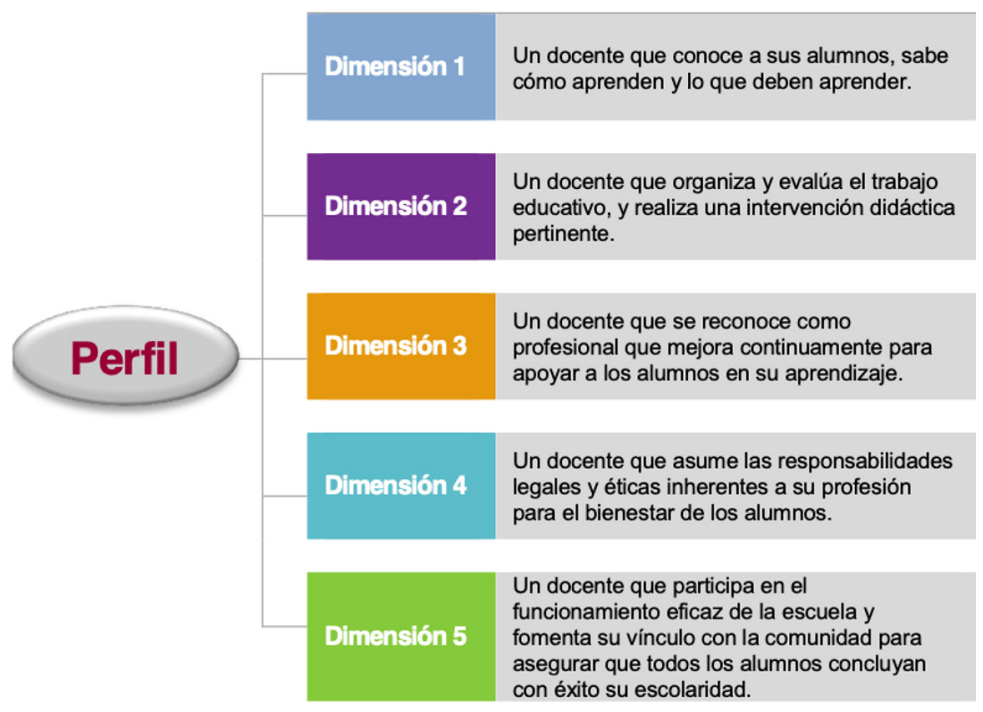

Figura 1. Muestra el perfil, parámetros e indicadores (PPI), para docentes y técnicos docentes de educación básica. Tomado de Coordinación Nacional del Servicio Profesional Docente, 2017. Disponible en http://servicioprofesionaldocente.sep.gob.mx/portal-docente-2014-2018/ content/ba/docs/2017/ingreso/PPI_INGRESO_EB_2017_2018.pdf.

en el diálogo, el respeto mutuo y la inclusión para generar un clima de confianza entre los alumnos» $\mathrm{y}$ «entre maestros y alumnos».

En relación con la dimensión 3, «un docente que se reconoce como profesional que mejora continuamente para apoyar a los alumnos en su aprendizaje»; y sus respectivos parámetros, identifica a la reflexión sistemática sobre la práctica docente para mejorarla; en ese sentido, Krishnamurti llamaba a la reflexión de la propia práctica a convertirse en observador sistemático de la experiencia, pues ambas -la práctica y la experiencia- son producto de la memoria y de la tradición, de las cuales hay que estar en vigilia perpetua para saber identificar los problemas cuando aparecen y encontrarles pronta solución gracias a la percepción inteligente. Aunque no dice expresamente sobre la utilización de referentes teóricos para el análisis de la práctica profesional, tampoco se manifiesta explícitamente en contra y en cambio alienta la preparación del profesor en todos los aspectos de los que debe ser especialista; es por eso por lo que iba a las escuelas a conversar con los educadores para que tomaran conciencia de la necesidad del cambio personal para desencadenar el cambio social; era partidario de la reflexión entre pares, pues proponía que para aprender a ser profesor de un centro escolar Krishnamurti era necesario que los nuevos profesores se socializaran en los mismos con el acompańamiento de los profesores ya instalados; también se evidencia en las profundas conversaciones que sostenía con los maestros para desentrañar sus propias acciones en beneficio de una educación que trascendiera las pedagogías tradicionales; pensaba que era necesaria 
la participación de las escuelas en redes, y un ejemplo de ello son los centros escolares Krishnamurti, que están conectados a pesar de que se encuentran en diferentes partes del mundo.

En cuanto a la dimensión 4, «un docente que asume las responsabilidades legales y éticas inherentes a su profesión para el bienestar de sus alumnos», en lo que se refiere a «establecer un ambiente favorable para la sana convivencia y la inclusión educativa»; considerar "la integridad y seguridad de sus alumnos en la escuela» y demostrar "altas expectativas sobre el aprendizaje de sus alumnos» (PPI, 2018), son preceptos que se pueden encontrar presentes en las ideas de Krishnamurti. Asimismo se pueden percibir esas ideas expuestas en el PPI, en la implementación de «formas de interacción democrática en el aula y en la escuela», definir «reglas junto con sus alumnos», «implementar estrategias con la comunidad escolar que fomenten actitudes de compromiso, colaboración y solidaridad para la sana convivencia» y el «comunicar a la familia del alumno sobre sus potencialidades y capacidades» (PPI, 2018), afirmaciones que pueden verse en los apartados de cultivar el cuidado y la protección de la humanidad y el medio ambiente y el de la reflexión social del educador.

La dimensión 5 se encuentra presente en el discurso educativo de Krishnamurti en el aseguramiento de la realización de acciones para la «colaboración de los padres de familia y distintas instituciones para apoyar la tarea educativa de la escuela" y considerar "las características culturales y lingüísticas de la comunidad en el trabajo de aula y la escuela» (PPI, 2018).

En síntesis, los saberes del educador en las ideas de Krishnamurti en contraste con el perfil, parámetros e indicadores del Servicio Profesional Docente mexicano se perciben en alguna medida en las cinco dimensiones, pero sin ser del todo claras, sino más bien como ideas que circulan en el ambiente de las prácticas mezcladas con otros sistemas de creencias docentes y que en su momento se expresaron por los profesores para la elaboración del PPI.

Por último, vale destacar que este trabajo ha tenido el propósito de hacer visible el discurso pedagógico de Jiddu Krishmnamurti como un ejemplar de la pedagogía oriental. Asimismo, descifrar qué tanto de ese discurso está presente en el PPI del Servicio Profesional Docente mexicano, entendiendo que a) los profesores construyen sus teorías implícitas como representaciones mentales que forman parte del sistema de conocimiento de un individuo e interviene en sus procesos de comprensión, memoria, razonamiento y planificación de la acción; b) las teorías implícitas son construcciones individuales que se construyen como conocimientos sociales mediante actividades y prácticas culturales; c) tienen un carácter biográfico e individual pero también situado que guían y orientan la toma de decisiones, las rutinas y las prácticas docentes para hacer frente a las contingencias de la enseñanza (Marrero, 1991, 1993, 2009).

Para Krishnamurti es importante que el profesor reflexione y observe atentamente el contexto y la sociedad para que esté en capacidad de discernir-mediante la reflexión y la observación- qué es lo que perjudica o beneficia una buena educación; la medida de la buena educación está centrada en el descubrimiento interior del individuo -tanto de profesores como estudiantes- pero también en el entorno para formar a una persona feliz y un profesional responsable que construya relacio- 
nes horizontales y de respeto mediante la conversación, la escucha atenta y la relación afectuosa, así como la responsabilidad de ofrecer soluciones inteligentes a los problemas del entorno social, lo cual implica una ruptura radical con las prácticas y experiencias del pasado.

Pensamos que el esfuerzo de desentrañar el discurso pedagógico de Krishnamurti resulta significativo para el estudio de las teorías implícitas, las cuales operan a nivel inconsciente y son el soporte de la resolución de los problemas de las prácticas rutinarias; visibilizar las creencias, los conocimientos, los pensamientos, los sentimientos, emociones, imágenes, símbolos, representaciones, etcétera -agazapados en las relaciones de la vida cotidiana-, mediante la observación y la reflexión sistemática de sí mismo, de la propia práctica y de la experiencia, en un proceso de socialización completamente distinto, negando sistemáticamente las huellas de la tradición, la memoria y las experiencias pasadas que han fabricado la conformación de sociedades violentas e inhumanas generación tras generación, lo que ha dado como resultado la crueldad y agresividad en las relaciones sociales. La idea es favorecer un giro hacia una transformación radical y humanizada de las relaciones sociales en los centros escolares que a su vez favorezcan un cambio fundamental en la sociedad. 


\section{REFERENCIAS BIBLIOGRÁFICAS}

Alarcón Viudes, V.M. (2007). «Krishnamurti: el encuentro con la verdad». A Parte Rei Revista de Filosofía, 52, disponible en línea: http://serbal.pntic.mec.es/-cmunoz11/viudes52.pdf.

Blau, E. (ed.) (2007). Krishnamurti. 100 años de sabiduría. Barcelona: Editorial Kairós.

Claris, L. (2013). «To Know is not enough: critical thinkig in a Krishnamurti School». Journal of the Krishnamurti School, 17, disponible en línea: http://www.journal.kfionline.org/issue17/to-know-is-not-enough-critical-thinking-in-a-krishnamurti-school.

Cordero, G., Vázquez, M. y Luna Serrano, E. (2015). «Metodología para el desarrollo del perfil del asesor pedagógico de educación básica». Cuadernos de Investigación Educativa, 6 (1), 89-108.

Jacoвo-García, H.M. (2009). El profesionalismo integrado. Un nuevo modo de ser educador. México: Plaza y Valdés.

Jacobo-García, H.M. (2006). Teoría educativa. Lo que todo profesional de la educación tiene que saber. México: UPN.

Krishnamurti, J. (1974). Educando al educador. México: Editorial Orión.

Krishnamurti, J. (1975). El conocimiento de uno mismo. México: Editorial Orión.

Krishnamurti, J. (1978). Krishnamurti y la educación. Barcelona: Edhasa.

Krishnamurti, J. (1983). Vivir de instante en instante. México: Editorial Orión.

Krishnamurti, J. (1985). Conferencias en Washington, D.C. Buenos Aires: Editorial Kier.

Krishnamurti, J. (1992). El propósito de la educación. Barcelona: Edhasa.

Krishnamurti, J. (1996). Pedagogía de la libertad. Barcelona: Oásis.

Krishnamurti, J. (1996a). Sobre el aprendizaje y la sabiduría. Barcelona: Kairós.

Krishnamurti, J. (1998). Reflexiones sobre el self. Madrid: Editorial EDAF.

Krishnamurti, J. (1999). Sobre el aprendizaje y la sabiduría. Barcelona: Editorial Kairós.

Krishnamurti, J. (2002). El arte de vivir. Barcelona: RBA.

Krishnamurti, J. (2003). Ser humano. El cambio radical de la mente. Madrid: Ed. EDAF, S.A.

Krishnamurti, J. (2007). La educación y el significado de la vida. Madrid: Ed. EDAF, S.L.

Krishnamurti, J. (2013). Aprender es vivir. Cartas a las escuelas. Madrid: Gaia.

Krishnamurti, J. (2013a). «On Enquiry». Journal of the Krishnamurti Schools, 16, disponible en línea: http://www.journal.kfionline.org/issue-16/on-enquiry.

Krishnamurti, J. (2018). Educar sin miedo. Barcelona: Ediciones Obelisco, S.L.

Krishnamurthy, Lommel y Clark (2010). «Teaching Academy, 2009». Journal of the Krishnamurti Schools, 14 .

Marrero-Acosta, J.E. (2009). El pensamiento re-encontrado. Barcelona: Octaedro.

Marrero-Acosta, J.E. (1993). «Las teorías implícitas del profesorado: vínculo entre la cultura y la práctica de la enseñanza», en M.J. Rodrigo, A. Rodríguez y J. Marrero (eds.). Las teorías implícitas una aproximación al conocimiento cotidiano. Madrid: Visor.

Marrero-Acosta, J.E. (1992). «Las teorías implícitas del profesorado: un puente entre la cultura y la práctica de la enseñanza", en A. Estebaranz y V. Sánchez (eds.). Pensamiento de profesores y desarrollo profesional, volumen I. Conocimiento y teorías implícitas (pp. 9-22). Sevilla, España: Universidad de Sevilla, Secretariado de Publicaciones. 
OnKar, V. (2012). «Our inner landscape». Journal of the Krishnamurti Schools, 15, disponible en línea: http://www.journal.kfionline.org/issue-15/our-inner-landscape.

Rueda-Rodriguez, A.C. (2007). La sintesis como herramienta del periodismo de ciencia. Tesis de licenciatura inédita. Facultad de Ciencias Políticas y Sociales, UNAM.

Secretaría de Educación Pública México. (2017). Perfil, parámetros e Indicadores para docentes y técnicos docentes. México: SEB/CNSPD.

Thapan, M. (2001). «Krishnamurti (1895-1986)». Perspectivas: revista trimestral de educación comparada, XXXI (2), 273-286. París: UNESCO. Oficina Internacional de Educación.

VICEns, J. (2001). «La libertad y la naturaleza en Krishnamurti». Cuadernos de Pedagogía, 303. 